\title{
Update on treatment options for Lambert-Eaton myasthenic syndrome: focus on use of amifampridine
}

\author{
This article was published in the following Dove Press journal: \\ Neuropsychiatric Disease and Treatment \\ 28 May 2011 \\ Number of times this article has been viewed
}

\section{Sabine Lindquist \\ Martin Stangel \\ Section Clinical Neuroimmunology and Neurochemistry, Department of Neurology, Hannover Medical School, Hannover, Germany}

\begin{abstract}
In Lambert-Eaton myasthenic syndrome (LEMS), antibodies against presynaptic voltage-gated calcium channels reduce the quantal release of acetylcholine, causing muscle weakness and autonomic dysfunction. More than half of the affected patients have associated small cell lung cancer, and thorough screening for an underlying malignancy is crucial. The mainstay of treatment for LEMS is symptomatic but immunotherapy is needed in more severely affected patients. Symptomatic therapies aim at increasing the concentration of acetylcholine at the muscle endplate. While acetylcholinesterase inhibitors were the first drugs to be used for the amelioration of symptoms, 3,4-diaminopyridine (3,4-DAP, amifampridine) has been shown to be more effective. 3,4-DAP blocks presynaptic potassium channels, thereby prolonging the action potential and increasing presynaptic calcium concentrations. This then results in increased quantal release of acetylcholine. The efficacy of 3,4-DAP for increasing muscle strength and resting compound muscle action potentials has been demonstrated by four placebo-controlled trials. Side effects are usually mild, and the most frequently reported are paresthesias. The most common serious adverse events are epileptic seizures. 3,4-DAP is currently the treatment of choice in patients with Lambert-Eaton myasthenic syndrome.
\end{abstract}

Keywords: Lambert-Eaton myasthenic syndrome, symptomatic treatment, management, 3,4-diaminopyridine, amifampridine

\section{An antibody-mediated syndrome}

Lambert-Eaton myasthenic syndrome (LEMS) is a disorder of the neuromuscular junction, characterized by proximal muscle weakness, depressed tendon reflexes, and posttetanic potentiation in addition to autonomic dysfunction. ${ }^{1-3}$ The clinical response of LEMS patients to plasma exchange ${ }^{4}$ and successful passive transfer experiments using patients' immunoglobulin ${ }^{4-6}$ led to discovery of serum antibodies to $\mathrm{P} / \mathrm{Q}$-type voltage-gated calcium channels as the cause of LEMS. ${ }^{7,8}$ These pathogenic antibodies cause a downregulation of voltage-gated calcium channels, lowering the amount of presynaptic calcium and thus reducing the quantal release of acetylcholine. ${ }^{9}$ For $10 \%-15 \%$ of voltage-gated calcium channel-antibody negative LEMS patients, other antibody targets, namely synaptotagmin and presynaptic M1 muscarinic acetylcholine receptors, have been discussed. ${ }^{10}$ Reduced acetylcholine release at the neuromuscular endplate results in decreased frequency of miniature endplate potentials of normal amplitude. Following a single nerve impulse, the acetylcholine released is not sufficient to activate most of the postsynaptic muscle fibers, therefore the compound muscle action potential (CMAP) is reduced. The CMAP shows a decrement at low stimulation frequency. In contrast, at high stimulation frequency, calcium is thought 
to accumulate in the nerve ending and facilitate acetylcholine release, resulting in the characteristic increment. A clinical correlate of this phenomenon is seen in improvement of previously absent tendon reflexes following a short period of forceful muscle contraction.

Autonomic dysfunction is present in the majority of LEMS patients and is usually mild. ${ }^{11}$ The most commonly reported symptoms are dry mouth and male impotence. Dry eyes, alterations in sudomotor function, constipation or impaired bowel control, and bladder dysfunction are also found frequently. ${ }^{11,12}$ Heart rate variability as a measure of parasympathetic innervation of the heart is more often affected than orthostatic regulation, which is a function of the sympathetic nervous system. ${ }^{12}$ Autoantibodies against voltage-gated calcium channels are also thought to underlie the autonomic dysfunction, although this view is not unchallenged. ${ }^{11}$ Sensorimotor neuropathy is not associated with autonomic symptoms in LEMS patients. ${ }^{11}$

LEMS is associated with small cell lung cancer in $50 \%-60 \%$ of patients, ${ }^{1,13}$ who show more rapidly progressive LEMS. Older age, a history of smoking, development of multiple clinical symptoms within the first 6 months, the presence of cerebellar symptoms, presence of Sox 1 antibodies, and absence of human leucocyte antigen B8 all increase the likelihood of associated small cell lung cancer. ${ }^{14}$ Recently, the Dutch-English LEMS Tumor Association Prediction (DELTA-P) score has been developed to distinguish more accurately between patients at high risk versus low risk for developing small cell lung cancer. ${ }^{15}$ The presence of LEMS appears to improve survival in patients with small cell lung cancer, either due to an immune-mediated effect or due to earlier diagnosis and treatment of the cancer. Small cell lung cancer is usually identified within 2 years of the diagnosis of LEMS. ${ }^{14,16}$

\section{Management}

The prognosis of LEMS is profoundly affected by associated small cell lung cancer. Therefore, diagnosis of LEMS should prompt a vigorous screen for small cell lung cancer, including computed tomography of the thorax, $\left[{ }^{18} \mathrm{~F}\right]$-fluordeoxyglucose positron emission tomography, and bronchoscopy. In the event of negative test results, these investigations should still be repeated every 6 months for at least 2 years. ${ }^{15,16}$ As yet, it is not clear if the DELTA-P score helps to identify patients in need of more intensive or prolonged screening.

Because LEMS is an antibody-mediated disease, immunotherapy is recommended for more severe cases.
Recommendations for conventional immunosuppression are similar to those for myasthenia gravis. ${ }^{17}$ Prednisolone plus a steroid-sparing agent, such as azathioprine, mycophenolate mofetil, cyclosporin, or methotrexate, is used. Plasmapheresis can stabilize the patient in a LEMS crisis. Alternatively, intravenous immunoglobulins have been shown in a small randomized, placebo-controlled, cross-over trial to improve limb strength in LEMS patients. ${ }^{18}$ However, immunosuppression is only recommended for patients in whom symptomatic treatment does not suffice. ${ }^{19}$ Thus, this review will focus on the nonimmune treatment options for LEMS, in particular the use of 3,4-diamionopyridine (3,4-DAP, amifampridine), which is now recommended as first-line therapy.

A literature search was performed using PubMed and the Cochrane Library. In addition, the assessment report of the European Medicines Agency for amifampridine (Zenas ${ }^{\circledR}$, now Firdapse ${ }^{\circledR}$ ) was consulted.

\section{Improving availability of acetylcholine at the muscle endplate}

Symptoms of LEMS are caused by reduced quantal release of acetylcholine. Therefore, symptomatic treatments aim to increase acetylcholine concentrations at the neuromuscular junction. Cholinesterase inhibitors block degradation of the transmitter and were the first symptomatic treament used in LEMS cases. ${ }^{20}$ However, the effects of monotherapy are at best minimal, ${ }^{21}$ and a double-blind, placebo-controlled, cross-over study found no effect of pyridostigmine on CMAP amplitude and muscle strength. ${ }^{22}$

Other symptomatic treatments are aimed at improvement of presynaptic acetylcholine release. Guanidine hydrochloride was first recommended by Lambert to treat LEMS, ${ }^{23}$ and can increase the concentration of free intracellular calcium by blocking the respiratory chain and potassium channels, thus prolonging the action potential at the nerve terminal, or facilitating calcium channels. In vitro studies have demonstrated that guanidine enhances the release of acetylcholine, particularly at the beginning of a tetanus, but not later during the tetanic train. This explains its effectiveness in LEMS with its low initial action potential and its limited use in myasthenia gravis. Guanidine has been shown to improve electromyographic parameters and muscle strength effectively in multiple case reports. ${ }^{21}$ However, guanidine has not been studied in controlled trials because serious side effects, especially bone marrow depression and renal failure, preclude widespread use of the drug. 
Aminopyridines selectively block presynaptic voltagedependent potassium channels, thereby prolonging cell membrane depolarization and allowing for more calcium to be transported into the nerve ending. The resulting increase in intracellular calcium facilitates the vesicular release of acetylcholine and enhances impulse transmission at central, autonomic, and neuromuscular synapses. 4-Aminopyridine (fampridine) was initially used in LEMS, but its use was limited by stimulating effects in the central nervous system, because it readily crosses the blood-brain barrier. Fampridine is twice as toxic and more convulsive than amifampridine in laboratory animals after intravenous administration. In vitro studies demonstrated that amifampridine is $7-10$ times more potent than fampridine in enhancing the quantal release of acetylcholine. ${ }^{25}$ Due to its better therapeutic index, amifampridine is now the drug of choice for the symptomatic treatment of LEMS.

\section{Pharmacology of 3,4-diaminopyridine Chemistry}

3,4-DAP is a quaternary ammonium compound that can be supplied as the base or as the more stable phosphate salt. It is water-soluble and only slightly soluble in organic solvents. Figure 1 shows the chemical structures of 3,4-DAP base and salt formulations compared with 4-aminopyridine and guanidine.

\section{Primary pharmacodynamics}

3,4-DAP blocks fast voltage-gated potassium channels, prolonging presynaptic depolarization and thus the action potential, resulting in increased release of acetylcholine. ${ }^{26,27}$ Additionally, a direct modulation of calcium channels by altered potassium channel function is suggested. ${ }^{28}$

The selective potassium channel-blocking characteristics of 3,4-DAP have been studied electrophysiologically in murine triangularis sterni preparations. ${ }^{29}$ At a concentration of $10 \mathrm{mM}, 3,4-\mathrm{DAP}$ has been found to be able to reverse a $70 \%$ reduction in twitch height induced by $1-5 \mathrm{mM}$ tubocurarine,

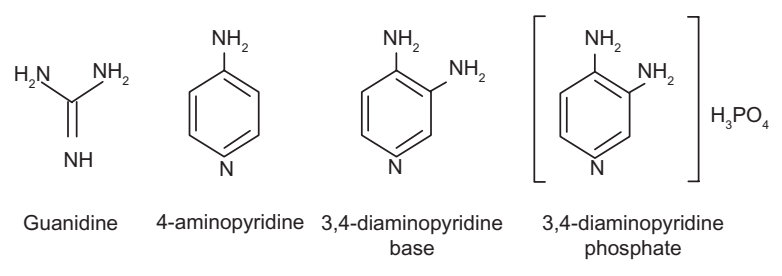

Figure I Chemical structures of potassium channel blockers used experimentally or clinically for the treatment of Lambert-Eaton myasthenic syndrome. a competitive acetylcholine antagonist. In a study of muscle preparations from young and old adult male Fisher rats, 3,4-DAP increased the isometric twitch force by $180 \%$ in tissue from young animals, whereas the increase was significantly lower (140\%) in older animals. ${ }^{30}$

\section{Secondary pharmacodynamics}

3,4-DAP can affect the cardiovascular, nervous, and gastrointestinal systems as part of its secondary pharmacodynamic profile. In vitro, 3,4-DAP can modulate cardiac conduction and induce phasic contractions in different arteries from several species. Additionally, 3,4-DAP can stimulate potassium-evoked dopamine and noradrenaline release in rat hippocampal slices and upregulate acetylcholine release in the brain. Finally, 3,4-DAP can potentiate adrenergic and cholinergic neuromuscular transmission in the gatrointestinal tract.

3,4-DAP has been demonstrated to increase blood pressure in a dose-dependent manner, induce salivation in the cat, and induce full dose-dependent miosis in anesthesized rats. ${ }^{31}$ There are no studies on secondary pharmacodynamics in humans.

\section{Pharmacokinetics}

There are limited data on the pharmacokinetics of 3,4-DAP. In a study of patients with multiple sclerosis, 3,4-DAP base was rapidly absorbed after oral administration and had a serum half-life from 20 minutes to 2 hours, with considerable inter-individual variability. ${ }^{32}$ After intravenous injection of $10 \mathrm{mg}$ into LEMS patients, peak plasma concentration $\left(\mathrm{C}_{\max }\right)$ was $68 \pm 19 \mathrm{ng} / \mathrm{mL}$, and the average plasma concentration half-life was $58 \pm 25$ (range 29-110) minutes. Compartmental analysis demonstrated a mean clearance of $1.97 \mathrm{~L} / \mathrm{min}$. The pharmacokinetics of 3,4-DAP were not significantly affected by cotreatment with pyridostigmine. ${ }^{22}$ In LEMS patients, clinical improvement is seen within 5 minutes of intravenous administration of 3,4-DAP $8-9 \mathrm{mg}$. The maximal effect after oral administration is seen after 1.5 hours, with treatment effects maintained for 3-8 hours. Effective oral doses are approximately three times those of the same doses given intravenously. ${ }^{33} \mathrm{~A}$ bioequivalence study (DAPSEL) comparing the 3,4-DAP base and phosphate salt formulations showed a higher $\mathrm{C}_{\max }$ and a shorter time to peak concentration for the salt. ${ }^{31}$

There are no human data for 3,4-DAP on protein binding, metabolism, excretion, or drug interactions apart from the data described above. ${ }^{22}$ There are also no data on special populations, such as those with hepatic or renal impairment. 


\section{Toxicity}

The $\mathrm{LD}_{50}$ is $13 \mathrm{mg} / \mathrm{kg}$ in mice after intravenous injection, $20 \mathrm{mg} / \mathrm{kg}$ after peritoneal injection, and $35 \mathrm{mg} / \mathrm{kg}$ after subcutaneous injection. Death in mice is due to uncontrolled convulsions. ${ }^{33}$

\section{Clinical use of 3,4-DAP}

The first report on the use of 3,4-DAP in LEMS patients showed marked improvement of muscle function in three women treated with 3,4-DAP 6-9 mg intravenously four times daily or $18 \mathrm{mg}$ orally four times daily. ${ }^{34} \mathrm{Up}$ until now, there have been four double-blind, placebo-controlled trials investigating the effectiveness of 3,4-DAP in LEMS, involving a total of 54 patients (Table 1). Three trials had a crossover design, and one had a parallel-group design. In all trial participants, the diagnosis of LEMS was based on a typical clinical picture, including proximal muscle weakness with or without absent tendon reflexes or dysautonomia, and confirmed by pathognomonic electrophysiological findings of decreased resting CMAP amplitude in a hand muscle, and facilitation of more than $100 \%$ after 10 seconds of maximal voluntary contraction. The primary outcome measure was a change in quantitative myasthenia gravis (QMG) score or limb muscle strength assessed by myometry. The secondary outcome measure was improvement in resting CMAP amplitude.

McEvoy et $\mathrm{al}^{35}$ studied 12 LEMS patients in a doubleblind, placebo-controlled, crossover pivotal trial. The first 8 days were conducted as an open-label phase, during which 3,4-DAP was given in increasing doses up to $25 \mathrm{mg}$ orally four times per day. In the double-blind, cross-over phase, patients were randomly assigned to either placebo or the maximally tolerated dose of 3,4-DAP for 3 days, and then received the alternate regimen for another 3 days. Outcome was measured using the neurological disability score, including strength of 25 muscles and the activity of five tendon reflexes, isometric strength of bilateral elbow and wrist flexion, knee extension, and ankle dorsiflexion, and electrophysiological parameters, ie, resting CMAP amplitudes, decrement during $2 \mathrm{~Hz}$ repetitive stimulation, and increment after 10 seconds of voluntary contraction on days $1,3,5,9,12$, and 15 . Additionally, autonomic function was assessed quantitatively at baseline and during the maximal dose of the open-label phase, including sweat production, salivation, orthostasis, and heart rate variability. The neurological disability score was lowered by treatment in the open-label phase and was significantly decreased compared with placebo in the double-blind phase. Isometric strength also improved significantly with treatment. Arm strength increased from $70 \%$ to $81 \%$ of normal, leg strength from $45 \%$ to $65 \%$. The average resting CMAP amplitudes increased from $2.9 \mathrm{mV}$ to $5.0 \mathrm{mV}$ in the arm and from $1.6 \mathrm{mV}$ to $3.1 \mathrm{mV}$ in the leg (compared with $2.8 \mathrm{mV}$ and $1.8 \mathrm{mV}$, respectively, after placebo). Decrements and increments showed no treatment-related changes, nor were any of the autonomic function tests altered, although all the patients complained of dry mouth $(n=6)$ but reported an improvement after treatment, suggesting that the tests for salivation were insensitive. Nine patients were followed up for 15 months on 3,4-DAP treament, four of whom had additional pyridostigmine. No significant decline in the effectiveness of 3,4-DAP was noted during this time. Ten of twelve patients noticed paresthesias while taking 3,4-DAP. Limitations of this study were the limited outcome measures and the lack of definition of primary or secondary outcome measures.

Table I Randomized, placebo-controlled trials with 3,4-diaminopyridine in patients with Lambert-Eaton myasthenic syndrome

\begin{tabular}{|c|c|c|}
\hline Reference & Trial design & Outcome \\
\hline McEvoy et $\mathrm{al}^{35}$ & $\begin{array}{l}\mathrm{n}=12 \text {, double-blind, placebo-controlled, cross-over, maximum } \\
\text { tolerated dose of 3,4-DAP (up to } 100 \mathrm{mg} / \text { day) for } 3 \text { days }\end{array}$ & $\begin{array}{l}\text { Improved NDS score, isometric muscle strength and } \\
\text { resting CMAP amplitudes, decrement and increment } \\
\text { unchanged, quantitative autonomic tests unchanged }\end{array}$ \\
\hline Sanders et $\mathrm{al}^{36}$ & $\begin{array}{l}\mathrm{n}=26(12 \text { with 3,4-DAP, } 14 \text { with placebo), parallel-group, } \\
3,4-\mathrm{DAP} 60 \mathrm{mg} / \text { day or placebo for } 6 \text { days }\end{array}$ & Improved QMG score and resting CMAP amplitudes \\
\hline Wirtz et $\mathrm{a}^{22}$ & $\begin{array}{l}\mathrm{n}=9 \text {, double-blind, placebo-controlled, double-dummy, } \\
\text { cross-over, 3,4-DAP } 10 \mathrm{mg} \text { IV, pyridostigmine } 2 \mathrm{mg} \mathrm{IV} \text {, both } \\
\text { drugs together or placebo, functional assessments every } \\
20 \text { minutes after administration up to } 170 \text { minutes }\end{array}$ & $\begin{array}{l}\text { Improved isometric muscle strength and resting CMAP } \\
\text { amplitudes }\end{array}$ \\
\hline Oh et a ${ }^{37}$ & $\begin{array}{l}n=8 \text {, double-blind, placebo-controlled, cross-over, 3,4-DAP } \\
\text { I5-80 mg/day orally or placebo for } 8 \text { days }(n=3) \text { or } \\
30-75 \mathrm{mg} / \text { day orally for } 3 \text { days }(n=4) \text {, one dropout }\end{array}$ & $\begin{array}{l}\text { Improvement of subjective symptoms Score, LEMS } \\
\text { classification, MRC score of } 22 \text { muscles and QMC as } \\
\text { well as resting CMAP amplitude, unchanged decrement } \\
\text { and increment }\end{array}$ \\
\hline
\end{tabular}

Abbreviations: 3,4-DAP, 3,4-diaminopyridine; CMAP, compound muscle action potential; IV, intravenous; LEMS, Lambert-Eaton myasthenic syndrome; MRC, Medical Research Council; QMG, quantitative myasthenia gravis. 
Sanders et $\mathrm{l}^{36}$ studied 26 LEMS patients in a two-arm, parallel-treatment protocol. Twelve patients were randomly assigned to 3,4-DAP $20 \mathrm{mg}$ three times per day for 6 days. The primary outcome measure was muscle strength assessed using the QMG score (range 0-39) on the fifth and sixth days of study drug administration. Changes in resting CMAP amplitudes were used as the secondary outcome measure. After six days, QMG scores were improved by an average of two points in the group receiving 3,4-DAP, but worsened by 0.25 points in the placebo group $(P=0.01)$. Median resting CMAP amplitudes showed an increase of $1.3 \mathrm{mV}$ $(+64 \%)$ in the patients receiving 3,4-DAP, but decreased by $0.1 \mathrm{mV}(3 \%)$ in the placebo group $(P<0.001)$. After the blinded phase, 25 patients continued taking 3,4-DAP, usually together with pyridostigmine. All but three patients improved by at least two QMG points while taking 3,4-DAP. In more than half of the patients, the optimum clinical response was achieved with $30 \mathrm{mg}$ or $40 \mathrm{mg}$ of 3,4-DAP per day. The authors mention that during the open-label phase, 13 patients who improved while taking open-label 3,4-DAP had a further symptomatic improvement when pyridostigmine was added, but this report was not backed up with quantitative data. Reported side effects were minimal. Four of 14 patients taking 3,4-DAP in the blinded phase and eight of 22 patients in the open-label phase complained of perioral and/or digital paresthesias. No changes in blood tests for renal, liver, hematologic, or endocrine function were observed acutely or after 6 months in the open-label phase.

Wirtz et $\mathrm{al}^{22}$ performed a randomized, placebo-controlled, double-dummy, cross-over study in nine voltage-gated calcium channel-positive LEMS patients. They compared the effects of 3,4-DAP, pyridostigmine, the combination of both drugs, and placebo, on muscle strength and results of repetitive nerve stimulation. They also included pharmacokinetic and pharmacodynamic data. Patients were treated with 3,4-DAP $10 \mathrm{mg}$ intravenously, pyridostigmine $2 \mathrm{mg}$ intravenously, both drugs, or placebo. Drug effects were measured every 20 minutes up to 170 minutes after administration. Isometric muscle strength of hip flexion and CMAP amplitudes of the hypothenar muscle were used as primary outcome measures, with a CMAP decrement after $3 \mathrm{~Hz}$ stimulation and an increment after maximum voluntary contraction used as secondary outcome measures. Muscle strength and CMAP amplitude increased significantly compared with placebo (mean-time averaged difference 23 Newtons and $0.9 \mathrm{mV}$, respectively) and with both drugs combined (26 Newtons and $1.1 \mathrm{mV}$, respectively), but not with pyridostigmine alone. The combination therapy provided a slight reduction in decrement compared with 3,4-DAP alone, but no other beneficial effects favoring the combination therapy were observed. Concentration-effect analysis revealed that the neuromuscular effects lasted longer than would be suggested by the 1-hour plasma half-life of 3,4-DAP, supporting a three to four times daily dosing regimen. Two patients withdrew from the study after three treatments due to pain in the arm at the injection site.

Oh et $\mathrm{al}^{37}$ conducted a randomized, crossover study in eight patients with LEMS. Pyridostigmine was discontinued for at least 24 hours before and during the trial. One patient withdrew from the study due to a treatment-related side effect after the first phase (chills, shortness of breath, weakness, upset stomach, and difficulty sleeping). Patient recruitment took place over 12 years and the study design was altered after the first three cases. The first group was treated for 8 days each in the 3,4-DAP and the placebo phase. For the second group, both phases were reduced to 3 days. The first group initially received 3,4-DAP $15 \mathrm{mg}$ which was gradually increased to $80 \mathrm{mg}$ in the active phase, the second group initially received 3,4-DAP $30 \mathrm{mg} /$ day which was gradually increased to $75 \mathrm{mg}$ /day in the active phase. Clinical outcome was assessed using a subjective symptoms score (range 0-3), the LEMS classification (a modified Medical Research Council [MRC] grade of iliopsoas muscles, range $0-3$ ), the MRC score of 22 muscles (range 0-110), and the QMG score. Electrophysiologically, CMAP amplitudes of abductor digiti quinti muscle, decremental response at $3 \mathrm{~Hz}$, increments after 30 seconds of exercise, and the results of single-fiber electromyography in the extensor digitorum communis muscle were examined. Patients treated with 3,4-DAP improved in all four clinical outcome measures compared with the placebo group. The highest statistical significance was demonstrated in the LEMS classification. While the median baseline value was 1 , it was 0 after 3,4-DAP treatment and 1.5 with placebo. Of the electrophysiological measures, only resting CMAP amplitudes showed a significant improvement (mean baseline $3.1 \mathrm{mV}$; 3,4-DAP $5.0 \mathrm{mV}$; placebo $2.4 \mathrm{mV}$ ). Four patients were followed up long-term in an open-label phase. Three patients received 3,4-DAP $30 \mathrm{mg} /$ day, with or without pyridostigmine, and two of them reported sustained benefit over 1 and 4 years, respectively. The third patient took 3,4-DAP up to $70 \mathrm{mg} /$ day, but then switched to guanidine hydrochloride due to a better clinical effect. The fourth patient discontinued 3,4-DAP and carried on with pyridostigmine monotherapy due to the lack of additional benefit from 3,4-DAP. ${ }^{37}$ Shortcomings of this study were the change in design during this study, with low 
numbers of participants and a lack of definition of primary and secondary outcome measures.

The 2011 update of the Cochrane review on treatment for LEMS summarizes the available data. ${ }^{38} \mathrm{~A}$ meta-analysis showed that the QMG score obtained after 3-8 days of treament was likely to improve by a mean of 2.44 points $(95 \%$ confidence interval [CI]: 1.22-3.6). The meta-analysis also revealed a mean improvement of the secondary endpoint, resting CMAP amplitudes, of $1.36 \mathrm{mV}$ (95\% confidence interval 0.99 to 1.72 ). The risk of bias was determined to be low and the quality of evidence moderate to high.

In addition, there are case reports on the effectiveness of 3,4-DAP to treat autonomic dysfunction. ${ }^{39,40}$ However, there may be a publication bias since negative outcomes are less likely to be published.

\section{Safety and tolerability of 3,4-diaminopyridine}

In total, about 2300 people have been exposed to 3,4-DAP, among these are around 300 LEMS patients. ${ }^{31}$ The most frequent serious adverse events are seizures. McEvoy et $\mathrm{al}^{35}$ reported a seizure in a patient shortly after the daily dose had been increased from $90 \mathrm{mg}$ to $100 \mathrm{mg}$ and the daily dose of pyridostigmine was doubled from $120 \mathrm{mg}$ to $240 \mathrm{mg}$. Seizures did not recur with a daily dose of 3,4-DAP $40 \mathrm{mg}$. In another study of 45 patients with LEMS treated with 3,4-DAP, three patients suffered seizures. One patient with metastatic cancer in the brain had a seizure when taking 3,4-DAP $60 \mathrm{mg} /$ day. The second patient developed seizures under cotreatment of 3,4-DAP $100 \mathrm{mg}$ /day and toxic doses of theophylline, but seizures did not recur after theophylline was discontinued. One patient with a seizure on $100 \mathrm{mg} /$ day continued to take 3,4-DAP at a lower dose and continued to be seizure-free over 10 years. The risk of seizures appears to be dose-dependent. Therefore, the authors recommend a maximal dose of $80 \mathrm{mg} /$ day. $^{36}$

Other reported serious adverse events are one case each of chorea and myoclonia. In the DAPSEL bioequivalence study, elevation of liver enzymes was seen in a previously healthy subject which returned to normal 1 month after discontinuation of 3,4-DAP. ${ }^{31}$

Serious cardiovascular events were reported in two cases. One followed iatrogenic intoxication and occurred in a 65-year-old woman receiving $60 \mathrm{mg}$ instead of $10 \mathrm{mg}$ six times per day. She presented with general weakness, whole body paresthesias, nausea and vomiting, and supraventricular tachycardia. She subsequently developed severe seizures with acute respiratory failure and cardiac arrest. After withdrawal of 3,4-DAP she recovered well. ${ }^{41}$ The second case was a myocardial infarction a few weeks after 3,4-DAP had been commenced. The authors considered the event to be a possible "result of sudden increase of physical activity". ${ }^{42}$ This study also reported bronchial hypersecretion and provocation of bronchial asthma.

Effects on QTc levels were examined in the DAPSEL study. No increase in QTc was observed, but only relatively low doses (3,4-DAP $10 \mathrm{mg}$ or $20 \mathrm{mg}$ ) were administered. One case report described a 57-year-old man with LEMS and euthyroid Hashimoto's disease, who was treated with 3,4-DAP $90 \mathrm{mg} / \mathrm{d}$ and azathioprine $100 \mathrm{mg} / \mathrm{d}$, and showed a slight prolongation of the QTc interval $(0.46 \mathrm{msec}$, normal range $0.36-0.44 \mathrm{msec}){ }^{31}$

Adverse events were reported in 51 LEMS patients from four placebo-controlled trials. Most commonly observed were perioral or digital paresthesias with daily doses as low as $10 \mathrm{mg}$, starting about 1 hour after oral administration of 3,4-DAP. Some patients complained of transient dizziness or fatigue. Symptoms resolved with dose reduction. Abdominal pain, epigastric distress, or abdominal cramps were also frequently reported to occur under treatment with 3,4-DAP. The adverse events reported in the placebo-controlled studies of LEMS patients are summarized in Table $2 .{ }^{43}$

The largest safety study of 3,4-DAP in clinical practice was carried out as an observational, retrospective cohort study involving 669 patients, mostly suffering from multiple sclerosis, but including three patients with LEMS. ${ }^{44}$ The patients with multiple sclerosis received 3,4-DAP 20-30 mg/ day, and the LEMS patients received higher doses of 30, 50 and $80 \mathrm{mg} /$ day. Six serious adverse events were reported, ie, three patients with de novo or aggravated seizures, one with left-sided paresthesias requiring hospitalization, and

Table 2 Adverse events related to 3,4-DAP treatment in Lambert-Eaton myasthenic syndrome

\begin{tabular}{lll}
\hline Adverse event & Patients $(\mathbf{n}=\mathbf{5 I})$ & $\%$ \\
\hline SAE & $\mathrm{I}$ & \\
Seizure & & \\
AE & 22 & 43 \\
Paresthesias & 6 & 12 \\
Fatigue & 6 & 12 \\
Epigastric distress & 5 & 10 \\
Sleeplessness & $\mathrm{I}$ & 2 \\
Shortness of breath & $\mathrm{I}$ & 2 \\
Increased tearing & $\mathrm{I}$ & 2 \\
Urinary urge & $8 / 9$ & 89 \\
Pain in arm of IV administration &
\end{tabular}

Note: Data from references ${ }^{22,35-37}$ as summarized in Wirtz et al. ${ }^{43}$

Abbreviations: 3,4-DAP, 3,4-diaminopyridine; AE, adverse events; SAE, serious adverse events; IV, intravenous. 
two with cardiovascular disorders. Drug-induced hepatitis was diagnosed in one patient with multiple sclerosis who had received 3,4-DAP $30 \mathrm{mg}$ /day and also had had four courses of mitoxantron. In total, $18.2 \%$ of the patients showed adverse events, most of which were mild to moderate and did not lead to discontinuation of the drug. Most common were paresthesias, followed by sleep disturbances, abdominal pain, and nausea and vomiting. ${ }^{44}$

In the DAPSEL study, 40 adverse events were reported in 26 healthy volunteers, 25 of which were paresthesias, mainly perioral as described in the 3,4-DAP-treated patients. All but one adverse event (elevation of liver enzymes as described above) were considered minor and did not lead to premature withdrawal.

In total, 114 patients were treated under the Therapeutic Use Protocol in France, and among these were 39 LEMS patients, with 25 adverse events in 13 case reports from eleven patients. Of the 13 reports, two were serious. The gastrointestinal system was most commonly affected by treatment-related adverse events (14.7\%), and the most common individual adverse events were paresthesias (4.9\%) and nausea and vomiting $(3.6 \%){ }^{31}$

Laboratory tests for renal, hematological, and endocrine functions have not revealed any adverse effects of 3,4-DAP. However, elevated liver enzymes were reported in one patient on a daily dose of $60 \mathrm{mg} /$ day, a healthy volunteer on a dose of $30 \mathrm{mg} /$ day, and a patient on $30 \mathrm{mg} /$ day with pretreatment elevation of gamma glutamyl transpeptidase. ${ }^{31}$ There are no data on safety in special populations, such as those with renal or hepatic impairment.

Because patients with LEMS are extremely sensitive to depolarizing and nondepolarizing muscle relaxants (succinylcholine, turbocurarine), reduced doses of these drugs should be used for neuromuscular blockade during anesthesia, and should be avoided where possible. If their use is required, neuromuscular transmission should be monitored closely. 3,4-DAP should be continued up to the time of surgery and recommenced as soon as possible. ${ }^{31}$

\section{Discussion}

Four placebo-controlled trials have demonstrated that 3,4-DAP effectively improves muscle strength and resting CMAP in patients with LEMS. Because autonomic symptoms are also caused by impaired acetylcholine release, 3,4-DAP should also treat dysautonomia in LEMS patients. However, despite anecdotal reports of effectiveness, McEvoy et $\mathrm{al}^{35}$ found no effect on several quantitative measures of autonomic function. This aspect should be studied further, bearing in mind the impact of autonomic dysfunction on quality of life in patients with LEMS. An additional effect of pyridostigmine used as a cotreatment with 3,4-DAP was claimed in several reports, but this was not supported by a recent small comparative trial. Larger trials may be needed to assess moderate treatment effects.

All the 3,4-DAP treatment trials used the base, either as a formulation for oral or for intravenous use. The availability of 3,4-DAP varies widely across Europe and the US, being distributed only through selected pharmacies, commonly associated with specialized centers. The more stable phosphate salt formulation of 3,4-DAP was granted orphan drug status in 2002 by the European Medicines Agency. In the US, 3,4-DAP also received orphan drug status by the Food and Drug Administration, but was not approved for general use, so was available only through ad hoc preparations in compounding pharmacies. In December 2009, 3,4-DAP phosphate received marketing authorization in the European Union for the symptomatic treament of LEMS in adults. However, the European Medicines Agency expressed concerns about the comparability of the pharmacokinetics of the 3,4-DAP base and phosphate salt formulations.

Because the most serious adverse events appear to be dose-dependent, the maximal daily dose was reduced from $80 \mathrm{mg}$ /day to $60 \mathrm{mg}$ /day. Further studies on safety issues with higher doses and on long-term efficacy are needed. The marketing authorization required a patient registry to be set up, including measures of efficacy and addressing several of the safety issues, including occurrence of seizures, movement disorders, cardiac effects, carcinogenicity, safety in special populations such as those with hepatic or renal impairment, and pharmacokinetic data. Additionally, a thorough QT/corrected QT study was requested by the European Medicines Agency. Because the metabolism of 3,4-DAP has neither been studied in vitro nor in vivo, the European Medicines Agency have requested in vitro studies assessing the enzymes involved in metabolism of 3,4-DAP and the influence of the drug on the activity of several liver enzymes. The potential for enzyme induction will be tested and metabolites of 3,4-DAP analyzed. Whether this additional postmarketing workup justifies the considerable price difference between the 3,4-DAP base formulation and the phosphate salt is currently a matter of debate between the manufacturer and several health authorities.

\section{Conclusion}

3,4-DAP is recommended as first-line symptomatic treatment in LEMS by the Task Force of the European 
Federation of Neurological Diseases. It should be offered to all patients suffering from this rare disease, which affects approximately one in 100,000 individuals in Europe and the US. Dosing is recommended to start at $5 \mathrm{mg}$ three times a day and can be increased up to $60 \mathrm{mg}$ /day in 3-4 daily doses. It is contraindicated in patients with epilepsy. A warning is issued regarding risk groups, dose-dependency, and comedication with drugs that lower the seizure threshold. With respect to cardiac function, 3,4-DAP is contraindicated in patients on sultopride, those with congenital QT syndromes, and those taking other drugs known to prolong the QTc interval or to promote torsades de pointes. A warning is issued regarding cotreatment with QTc-prolonging drugs. Clinical and electrocardiographic monitoring is recommended at initiation of the drug and yearly thereafter. 3,4-DAP is also contraindicated in patients with uncontrolled asthma, who should be closely monitored. While 3,4-DAP will remain the drug of choice for LEMS patients in the coming years, ultimately there is a need to develop specific immunotherapies targeting their aberrant production of pathogenic antibodies.

\section{Disclosure}

The authors report no conflicts of interest in this work.

\section{References}

1. Lambert EH, Eaton LM, Rooke ED. Defect of neuromuscular conduction associated with malignant neoplasms. Am J Physiol. 1956;187: $612-613$.

2. Lambert EH, Elmqvist D. Quantal components of end-plate potentials in the myasthenic syndrome. Ann N Y Acad Sci. 1971;183:183-199.

3. O'Neill JH, Murray NM, Newsom-Davis J. The Lambert-Eaton myasthenic syndrome. A review of 50 cases. Brain. 1988;111(Pt 3): 577-596.

4. Lang B, Newsom-Davis J, Wray D, Vincent A, Murray N. Autoimmune aetiology for myasthenic (Eaton-Lambert) syndrome. Lancet. 1981;2: 224-226.

5. Lang B, Newsom-Davis J, Prior C, Wray D. Antibodies to motor nerve terminals: An electrophysiological study of a human myasthenic syndrome transferred to mouse. J Physiol. 1983;344:335-345.

6. Fukunaga H, Engel AG, Lang B, Newsom-Davis J, Vincent A. Passive transfer of Lambert-Eaton myasthenic syndrome with IgG from man to mouse depletes the presynaptic membrane active zones. Proc Natl Acad Sci U S A. 1983;80:7636-7640.

7. Motomura M, Johnston I, Lang B, Vincent A, Newsom-Davis J. An improved diagnostic assay for Lambert-Eaton myasthenic syndrome. J Neurol Neurosurg Psychiatry. 1995;58:85-87.

8. Lennon VA, Kryzer TJ, Griesmann GE, et al. Calcium-channel antibodies in the Lambert-Eaton syndrome and other paraneoplastic syndromes. N Engl J Med. 1995;332:1467-1474.

9. Lang B, Newsom-Davis J, Peers C, Prior C, Wray DW. The effect of myasthenic syndrome antibody on presynaptic calcium channels in the mouse. J Physiol. 1987;390:257-270.

10. Takamori M. Lambert-Eaton myasthenic syndrome: Search for alternative autoimmune targets and possible compensatory mechanisms based on presynaptic calcium homeostasis. J Neuroimmunol. 2008; 201-202:145-152.
11. O'Suilleabhain P, Low PA, Lennon VA. Autonomic dysfunction in the Lambert-Eaton myasthenic syndrome: Serologic and clinical correlates. Neurology. 1998;50:88-93.

12. Waterman SA. Autonomic dysfunction in Lambert-Eaton myasthenic syndrome. Clin Auton Res. 2001;11:145-154.

13. Titulaer MJ, Wirtz PW, Kuks JB, et al. The Lambert-Eaton myasthenic syndrome 1988-2008: A clinical picture in 97 patients. J Neuroimmunol. 2008;201-202:153-158.

14. Titulaer MJ, Verschuuren JJ. Lambert-Eaton myasthenic syndrome: Tumor versus nontumor forms. Ann NY Acad Sci. 2008;1132: 129-134.

15. Titulaer MJ, Maddison P, Sont JK, et al. Clinical Dutch-English Lambert-Eaton myasthenic syndrome (LEMS) tumor association prediction score accurately predicts small-cell lung cancer in the LEMS. J Clin Oncol. 2011;29:902-908.

16. Titulaer MJ, Soffietti R, Dalmau J, et al. Screening for tumours in paraneoplastic syndromes: Report of an EFNS task force. Eur J Neurol. 2011;18:19-e3.

17. Farrugia ME, Vincent A. Autoimmune mediated neuromuscular junction defects. Curr Opin Neurol. 2010;23:489-495.

18. Bain PG, Motomura M, Newsom-Davis J, et al. Effects of intravenous immunoglobulin on muscle weakness and calcium-channel autoantibodies in the Lambert-Eaton myasthenic syndrome. Neurology. 1996;47:678-683.

19. Skeie GO, Apostolski S, Evoli A, et al. Guidelines for treatment of autoimmune neuromuscular transmission disorders. Eur J Neurol. 2010;17:893-902.

20. Anderson HJ, Churchill-Davidson HC, Richardson AT. Bronchial neoplasm with myasthenia: Prolonged apnoea after administration of succinylcholine. Lancet. 1953;265:1291-1293.

21. Verschuuren JJ, Wirtz PW, Titulaer MJ, Willems LN, van Gerven J. Available treatment options for the management of Lambert-Eaton myasthenic syndrome. Expert Opin Pharmacother. 2006;7:1323-1336.

22. Wirtz PW, Verschuuren JJ, van Dijk JG, et al. Efficacy of 3,4diaminopyridine and pyridostigmine in the treatment of Lambert-Eaton myasthenic syndrome: A randomized, double-blind, placebo-controlled, crossover study. Clin Pharmacol Ther. 2009;86:44-48.

23. Lambert EH. Defects of neuromuscular transmission in syndromes other than myasthenia gravis. Ann NY Acad Sci. 1966;135:367-384.

24. Lemeignan M, Millart H, Lamiable D, Molgo J, Lechat P. Evaluation of 4-aminopyridine and 3,4-diaminopyridine penetrability into cerebrospinal fluid in anesthetized rats. Brain Res. 1984;304:166-169.

25. Molgó J, Lundh H, Thesleff S. Potency of 3,4-diaminopyridine and 4-aminopyridine on mammalian neuromuscular transmission and the effect of pH changes. Eur J Pharmacol. 1980;61:25-34.

26. Huang HY, Hertting G, Allgaier C, Jackisch R. 3,4-Diaminopyridineinduced noradrenaline release from CNS tissue as a model for action potential-evoked transmitter release: Effects of phorbol ester. Eur J Pharmacol. 1989;169:115-123.

27. Maddison P, Newsom-Davis J, Mills KR. Effect of 3,4-diaminopyridine on the time course of decay of compound muscle action potential augmentation in the Lambert-Eaton myasthenic syndrome. Muscle Nerve. 1998;21:1196-1198.

28. Hong SJ, Chang CC. Facilitation by 3,4-diaminopyridine of regenerative acetylcholine release from mouse motor nerve. Br J Pharmacol. 1990;101:793-798.

29. Braga MF, Harvey AL, Rowan EG. Effects of tacrine, velnacrine (HP029), suronacrine (HP128), and 3,4-diaminopyridine on sceletal neuromuscular transmission in vitro. $\mathrm{Br} J$ Pharmacol. 1991;102:909-915.

30. Van Lunteren E, Moyer M. Electrophysiologic and inotropic effects of $\mathrm{K}+$ channel blockade in aged diaphragm. Am J Respir Crit Care Med. 1998;158:820-826.

31. European Medicines Agency. Assessment report for Zenas ${ }^{\circledR}$. Procedure No. EMEA/H/C/001032. Available from: http://www.ema.europa.eu/ docs/en_GB/document_library/EPAR_-_Public_assessment_report/ human/001032/WC500069918.pdf. London, UK: European Medicines Agency; 2009. 
32. QuartelA, Turbeville S, Lounsbury D. Current therapy for Lambert-Eaton myasthenic syndrome: Development of 3,4-diaminopyridine phosphate salt as first-line symptomatic treatment. Curr Med Res Opin. 2010;26:1363-1375.

33. Sanders DB. 3,4-Diaminopyridine (DAP) in the treatment of LambertEaton myasthenic syndrome (LEMS). Ann N Y Acad Sci. 1998;841: 811-816.

34. Lundh H, Nilsson O, Rosén I. Novel drug of choice in Eaton-Lambert syndrome. J Neurol Neurosurg Psychiatry. 1983;46:684-685.

35. McEvoy KM, Windebank AJ, Daube JR, Low PA. 3,4-diaminopyridine in the treatment of Lambert-Eaton myasthenic syndrome. New Engl J Med. 1989;321:1567-1571.

36. Sanders DB, Massey JM, Sanders LL, Edwards LJ. A randomized trial of 3,4-diaminopyridine in Lambert-Eaton myasthenic syndrome. Neurology. 2000;54:603-607.

37. Oh SJ, Claussen GG, Hatanaka Y, Morgan MB. 3,4-Diaminopyridine is more effective than placebo in a randomized, double-blind, cross-over drug study in LEMS. Muscle Nerve. 2009;40:795-800.

38. Keogh M, Sedehizadeh KH, Maddison P. Treatment for Lambert-Eaton myasthenic syndrome. Cochrane Database Syst Rev. 2011;(2): CD003279.
39. Lundh H, Nilsson O, Rosén I. Treatment of Lambert-Eaton syndrome: 3,4-diaminopyridine and pyridostigmine. Neurology. 1984;34: 1324-1330.

40. Satoh K, Motomura, M, Suzu H, et al. Neurogenic bladder in LambertEaton myasthenic syndrome and its reponse to 3,4-diaminopyridine. Clin Auton Res. 2001;11:145-154.

41. Boerma CE, Rommes JH, van Leeuwen RB, Bakker J. Cardiac arrest following a iatrogenic by 3,4-diaminopyridine intoxication in a patient with Lambert-Eaton myasthenic syndrome. J Toxicol Clin Toxicol. 1995;33:249-251.

42. Lundh H, Nilsson O, Rosen I, Johansson S. Practical aspects of 3,4diaminopyridine treatment of the Lambert-Eaton myasthenic syndrome. Acta Neurol Scand. 1993;88:136-140.

43. Wirtz PW, Titulaer MJ, Gerven JM, Verschuuren JJ. 3,4-diaminopyridine for the treatment of Lambert-Eaton myasthenic syndrome. Expert Rev Clin Immunol. 2010;6:867-874.

44. Flet L, Polard E, Guillard O, et al. 3,4-Diaminopyridine safety in clinical practice: An observational, retrospective cohort study. J Neurol. 2010;257:937-946.
Neuropsychiatric Disease and Treatment

\section{Publish your work in this journal}

Neuropsychiatric Disease and Treatment is an international, peerreviewed journal of clinical therapeutics and pharmacology focusing on concise rapid reporting of clinical or pre-clinical studies on a range of neuropsychiatric and neurological disorders. This journal is indexed on PubMed Central, the 'PsycINFO' database and CAS, and is the officia

\section{Dovepress}

journal of The International Neuropsychiatric Association (INA). The manuscript management system is completely online and includes a very quick and fair peer-review system, which is all easy to use. Visit http://www.dovepress.com/testimonials.php to read real quotes from published authors.

Submit your manuscript here: http://www.dovepress.com/neuropsychiatric-disease-and-treatment-journal 